\title{
Management of poor quality pastures for maximum animal performance during summer
}

J.D. MORTON

AgResearch, Canterbury Agriculture \& Science Centre, P 0 Box 60, Lincoln, Canterbury

\section{Abstract}

A trial was carried out near Greymouth on the west coast of the South Island in 1987 and 1988 to determine production responses of thin and fat ewes to two feeding treatments from weaning to mating. At weaning in early January, 192 three-year-old Perendale ewes were individually condition scored and allocated into two equal-sized groups of thin (mean condition score $=2.7$, mean liveweight $=$ $41.4 \mathrm{~kg}$ ) and fat (mean condition score $=3.3$, mean liveweight $=46.8 \mathrm{~kg}$ ) ewes. From weaning to the start of mating in mid-April, each thin and fat ewe group were split evenly and grazed in a leader and follower system. The leader group was preferentially fed by having first choice while the follower group had the second choice of pasture. The pasture was of low nutritive value because of a low content of ryegrass and white clover and a high content of unimproved grasses, dead material and weeds. Preferential feeding resulted in significant increases in liveweight $(+4.5 \mathrm{~kg}$ for thin ewes, $+\mathbf{+ 5 . 1}$ $\mathrm{kg}$ for fat ewes) and condition $(+0.26$ condition score units for thin and fat ewes) compared with follow-up feeding. Increases in ovulation rate at the start of mating from preferential compared with follow-up feeding were higher for thin (1.35 vs 1.01) compared with fat (1.44 vs 1.21) ewes. There was little difference in the response in wool production to preferential feeding for thin (1 .0 1 vs $0.82 \mathrm{~kg} / \mathrm{ewe})$ compared with fat (1.11 vs $0.91 \mathrm{~kg} /$ ewe). Preferential feeding of thin ewes and the use of fat ewes to follow-up and clean out pastures from weaning to mating reduced the range of ewe liveweight at mating (42-54 kg) compared with grazing thin and fat ewes in a follow-up role (36-60 $\mathrm{kg}$ ). This would help standardise individual ewe feed requirements and allow ewes to be grazed in one mob during autumn and winter. Preferential feeding of thin ewes from weaning to mating was tested on twocommercial sheep farms and resulted in similar changes in ewe liveweight and condition as found in this reported trial.

Keywords preferential, follow-up, feeding, ewes, liveweight, condition, ovulation rate, wool produc tion

\section{Introduction}

On the west coast of the South Island. the high annual rainfall $(1700-4000 \mathrm{~mm})$ ensures reliable summer pasture growth and allows some recovery of ewe liveweight from weaning to mating which affects both ovulation rate (Rattray et al. 1980) and wool growth (Hawker et al. 1982). Since pasture growth rates $(50-60 \mathrm{~kg} \mathrm{DM} / \mathrm{ha} /$ day) exceedewe and lamb feed requirements during summer, pasture can become rank and be of low digestibility. Lack of ryegrass and white clover also results in pasture of low nutritive value. This is caused by sub-optimal applications of lime and fertiliser on recently developed soils of low natural fertility. At weaning, there is a wide range of individual ewe liveweight in any flock depending on frame size and the number and size of lambs reared during lactation. Ewe body condition (Russell et al. 1969) at weaning could be a more effective measure of the ability of the ewe to respond to feeding from weaning to mating than liveweight since body condition is independent of frame size. M ost of the previous research carried out in New Zealand on ewe recovery from weaning to mating has been on light and heavy ewes selected on the basis of liveweight (Kelly et al. 1983; Thompson et al. 1983).

The trial described in this paper compared the effect of preferential and follow-up feeding on the productive performance of thin and fat ewes grazing pasture with a low content of improved species over the period from weaning to mating.

\section{Methods}

The trial was conducted at Coal Creek Farm Settlement, a former Landcorp development block near Greymouth on the west coast of the South Island in 1987 and 1988. The mean annual rainfall for these two years was 2500 $\mathrm{m} \mathbf{m}$.

At weaning on 6 January, 192 3-year-old Perendale ewes were taken from a commercial flock and individually condition scored according to Russell (1984). The ewes weredivided equally into groups of thin (condition score 3 and below) and fat (condition score 3 and above) ewes. Half of each of the groups of thin and fat ewes was randomly allocated to one of two equal-sized feeding treatments. The two feeding treatments consisted of a 
leader group which was preferentially fed by having first choice of pasture and a follow-up group which was offered the second restricted choice of pasture.

The four treatment groups were:

1 Thin ewes, preferentially fed from weaning to mating.

2 Thin ewes, follow-up feeding from weaning to mating.

3 Fat ewes, preferentially fed from weaning to mating.

4 Fat ewes, follow-up feeding from weaning to mating.

From weaning to the startofmating in mid-April the four groups were rotationally grazed around 12 paddocks (averaging 1.4 ha in area) and shifted weekly with the thin and fat follow-up groups grazing the paddocks initially grazed by the respective thin and fat preferential feeding groups during the previous week. Pre- and postgrazing pasture mass for each treatment is shown in Table 1. For each 6 weekrotation. the same paddock was alternately grazed by thin and fat ewes. The 5 year old pasture was of low nutritive value due to a low percentage of ryegrass and legumes (mainly white clover) and a high percentage of weeds (mainly Juncus spp) and unimproved grasses (Figure 1). Unimproved grasses consisted of browntop, Yorkshire Fog, Poa species, sweet vernal, goose grass (Bromus mollis) andchewings fescue.

Table 1 Pre- and post-grazlng pasture mass for each treatment $(\mathrm{kg}$ DMha) , mean of 1987 and 1988.

\begin{tabular}{cccc}
\hline & \multicolumn{2}{c}{ Treatment } & \multicolumn{2}{c}{ Pasture mass (kg DWha) } \\
\hline $\begin{array}{l}\text { Ewe condition } \\
\text { at weaning }\end{array}$ & $\begin{array}{c}\text { Foeding from } \\
\text { weaning to mating }\end{array}$ & Pm-grazing Post-grazing \\
& & & \\
Thin & Preferential & 2220 & 1710 \\
Thin & Follow-up & 1710 & 1245 \\
Fat & Preferential & $\mathbf{2 1 8 0}$ & 1770 \\
Fat & Follow-up & $\mathbf{1 7 7 0}$ & 1235 \\
\hline
\end{tabular}

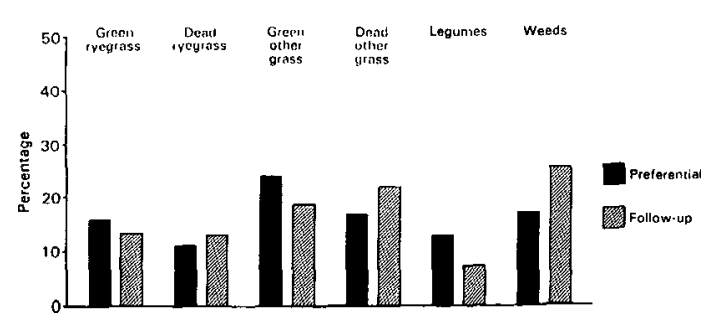

Figure 1 Composition of pasture grazed by preferential and follow-up ewes (averaged for cwe condition)
Pasture mass was assessed weekly from 50 capacitance probe readings per paddock corrected by cutting three $0.1 \mathbf{m}^{\mathbf{2}}$ pasture quadrats about the paddock mean to ground level and measuring actual pasture dry matter mass. The ewes were weighed after a 16-hour fast and condition scored by palpitating the ewe on and around the backbone in the loin area (Russell 1984) monthly. Wool was clipped from a $0.01 \mathbf{~ m}^{2}$ patch $\boldsymbol{o n}$ the mid side on 27 ewes per treatment group at weaning and the start of mating to measure greasy wool production. This measurement was adjusted using covariate analysis according to wool production measured during the pretrial period. At the start of mating (15 April, 1987 and 1988) each ewe was laparoscoped and the number of corpora lutea per ewe ovulating counted to measure ovulation rate after CIDR's had been used to synchronise the onset of oestrus.

During mating (mid-April to the end of May), the preferentially fed thin and fat ewes were combined into one group and the follow-up thin and fat ewes combined into another group and the feeding treatments continued.

For the period from the end of mating in 1987 to weaning in 1988 the ewes were grazed in one mob. It was not feasible to measure the lambing performance of the ewes because a commercial farming operation was being carried out on the site.

The data for ewe condition, liveweight, ovulation rate and wool production were subjected to analysis of variance according to a $2 \times 2$ factorial design.

\section{Results}

Although the apparent daily pasture intake of both the preferential and follow-up ewes was similar (Table 1), the follow-up ewes grazed pasture with less green grass and legume and more weeds and dead material (Figure 1) to a lower post-grazing pasture mass (Table 1) than the preferentially fed ewes. Hence the preferentially fed thin and fat ewes gained significantly $(P<0.05)$ more liveweight and condition respectively during the trial period than the follow-up thin and fat ewes (Table 2). This better feeding and liveweight gain allowed the preferentially fed thin and fat ewes to have a significantly $(P<0.05)$ higher ovulation rate at the start of mating and wool production from weaning to mating compared with the follow-up thin and fat ewes respectively (Table 3). There was no significant difference $(\mathrm{P}<0.05)$ in liveweight gain or wool production between preferentially fed thin and fat and follow-up thin and fat ewes. Preferential feeding of thin compared to fat ewes and follow-up. feeding of thin compared to fat ewes resulted in a significantly greater $(\mathbf{P}<0.05)$ gain in condition score. Ovulationrate at the start of mating was significantly higher $(\mathbf{P}<\mathbf{0 . 0 5})$ for follow-up fat than fol- 
low-up thin ewes. There was no significant difference $(P<0.05)$ in ovulation rate between preferential thin and preferential fat ewes.

Table 2: Effect of ewe condition and feeding on change in ewe liveweight $(\mathrm{kg})$ and condition score from weaning to mating - mean of 1987 and 1988

Treatment

Change In

Ewe condition Feeding from Livewelght Condition score at weaning weaning to mating

\begin{tabular}{llll}
\hline Thin & Preferential & 5.7 & 0.51 \\
Thin & Follow-up & 1.2 & 0.25 \\
Fat & Preferential & 5.2 & 0.28 \\
Fat & Follow-up & 0.1 & 0.02 \\
LSD $(5 \%)$ & & 2.9 & 0.17 \\
\hline
\end{tabular}

Note:

1 Initial ewe livewoight at weaning $\mathbf{a} 41.4 \mathrm{~kg}$ for thin ewes and 46.8 $\mathrm{kg}$ for fat ewes

2 Initial condition score at weaning $=2.7$ for thin ewes and 3.3 for fat ewes

Table 3: Effect of ewe condition and feeding on ewe ovulation rate at the start of mating and wool production (kg/ewe) from weaning to mating mean of 1987 and 1988.

\begin{tabular}{clcc}
\hline Treatment & & $\begin{array}{c}\text { Ovulation } \\
\text { rate }\end{array}$ & $\begin{array}{c}\text { Woof } \\
\text { production }\end{array}$ \\
$\begin{array}{c}\text { Ewe condition } \\
\text { weaning }\end{array}$ & $\begin{array}{c}\text { Feeding from } \\
\text { weaning to mating }\end{array}$ & & (kg/owe) \\
\hline ThIn & Proferential & $\mathbf{1 . 3 5}$ & 1.01 \\
ThIn & Follow-up & 1.01 & 0.82 \\
Fat & Preferential & 1.44 & 1.11 \\
Fat & Follow-up & 1.21 & 0.91 \\
LSD (5\%) & & 0.20 & 0.19 \\
\hline
\end{tabular}

\section{Discussion}

\section{Ewe condition at weaning}

In any flock, ewe condition at weaning is a function of condition at lambing, the level of feeding during lactation and the number and growth rate of lambs reared. Hence there is usually a wide range of ewe condition at weaning that differs from the distribution of liveweight because of the different frame size of individual ewes. At weaning ewes will range in liveweight from light to heavy (depending on both frame size and condition) and in condition from thin to fat (depending on loss of condition during lactation). The interaction of ewe liveweight and condition will create four broad categories of ewes: heavy/fat, heavy/thin, light/fat and light thin. Probably, the heavy/thin ewes would lose most condition during lactation owing to the rearing of twins or heavier lambs and therefore require higher levels of feeding from weaning to mating to recover this condition. Kelly et al. (1983) argued that it was worthwhile to preferentially feed only well grown ewes of high potential performance (heavy/thin) before mating rather than thin ewes that were light due to inferior genetic quality or Poor rearing (light/thin). In this trial the thin ewe groups were a mixture of heavy/thin and light/thin ewes. Unless genetically superior or well grown ewes can be identified at weaning according to frame size or high performance as measured by the number or weight of lambs reared, it is not possible to select the animals that will give the best response to extra feed from weaning to mating.

\section{Summer grating management}

In pastures where there is a lack of improved pasture species (ryegrass and white clover) the trial results indicate that ewes can recover liveweight if they have first choice of the pasture at a high allowance $(4-5 \mathrm{~kg}$ DM/ewe/day). Similar ewe liveweight gains to those measured in this trial $(5-6 \mathrm{~kg})$ have been reported by Thompson et al. (1990) at a similar pasture allowance. This type of lenient grazing results in a high postgrazing pasture mass dominated by less digestible pasture components (dead material and weeds). If pasture of adequate digestibility is to be maintained to achieve liveweight gain through several grazings, the residual pasture has to be hard grazed by another mob of stock. Such grazing results in maintenance of liveweight only as shown by the follow-up groups of trial ewes. Although the post-grazing pasturemass for these ewes was still high (1740 $\mathrm{kg} \mathbf{D M} / \mathrm{ha}$ ) most of the pasture consisted of dead material, grass stem and rushes with a high dry matter content but low digestibility.

\section{Ewe liveweight at mating}

In a commercial flock, ewe liveweight at mating is considered to be a more meaningful indicator of reproductive performance than ewe condition (Kelly et al. 1983). since it includes bothcondition and frame size. In this trial Preferential and follow-up feeding of both thin and fat ewes from weaning to mating resulted in a similar liveweight gain. Other workers (Kelly et al. 1983; Thompsonet al. 1983) reportedlittle difference in liveweight gain for light and heavy ewes at a similar pasture allowance to the preferentially fed group. Despite the similarity in liveweight gain between weaning and mating, fat ewes were still heavier at the start of mating than thin ewes under both feeding treatments because of higher initial liveweight at weaning. 
Although preferential feeding increased ewe liveweight at the start of mating to a similar degree $(+4-5 \mathrm{~kg}$ ) for both thin and fat ewes, the response in ovulation rate to better feeding was higher for thin (1.35 vs 1.01) than fat (1.44 vs 1.21 ) ewes. This result was in contrast to that found by Kelly et al. (1983). who found that the increase in ovulation rate to a generous feed allowance was similar for light and heavy ewes that gained $6-8 \mathrm{~kg}$ of liveweight for 6 weeks before the start of mating. In contrast to ovulation rate. wool production responses to preferential feeding were similar for both thin and fat ewes. This result was in agreement with that found by Kelly et al. (1983) for light and heavy ewes.

Preferentially feeding thin rather than fat ewes and using fat rather than thin ewes to follow-up also has the advantage of reducing the variation in ewe liveweight at the start of mating. In this trial, preferential feeding of thin ewes and using fat ewes to follow-up resulted in a narrower range of individual ewe liveweight at mating (42-54 kg) compared with using both thin and fat ewes in a follow-up role (36-60 kg). Ewe liveweight at weaning ranged from 33 to $62 \mathrm{~kg}$. A narrow range of ewe liveweight at the start of mating would be desirable since it simplifies management through having relatively uniform individual ewe feed requirements during autumn and winter.

\section{Condition scoring technique}

The relationship between condition scoring and liveweight showed that each condition score represented $11.5 \mathrm{~kg}$ of liveweight on average in this trial. This is in line with the relationship reported by Russell et al. (1984) but higher than that reported by Kelly et al. (1983). In this trial, change in condition score in relation to liveweight change was underestimated for the fat, preferentially fed ewes. It was more difficult to maintain consistency of condition scoring in ewes at scores above 3.5 compared with lower scores.

The practical operation of separating thin ewes at weaning involves working around a condition score cut off point and does not require accurate assessment of each ewe. For this trial, the cut off condition score was 3 to ensure that there was an equal number of ewes in the thin and fat treatment groups. In practice this cut off point would vary with overall ewe condition and the proportion of the flock that was considered appropriate for a preferential feeding group.

\section{On-farm testing}

Before the start of the reported trial, the concept of preferentially feeding thin ewes was tested on mobs of 1005 and 1995 Perendale ewes on two West Coast sheep farms. Since the ewes on both farms were in poorer condition than the trial ewes, the cut off point used at weaning was a condition score of 2.25 . This resulted in groups of 405 and 555 thin ewes respectively at each farm with an average initial condition score of 1.9 (average ewe liveweight $=42.8 \mathrm{~kg}$ ). The remaining fatter ewes had an average initial condition score of 2.7 (average ewe liveweight $=47.2 \mathrm{~kg}$ ). The thin ewes were selected by individually condition scoring each ewe as described for the trial and marking those below the cut off point

From weaning (mid-January) to the start of mating (mid-April), the preferentially fed ewes were given first choice of pasture or second choice behind a mob of lambs. During this period these ewes gained $8.1 \mathrm{~kg}$ of liveweight (1.2 condition score units) to average $50.9 \mathrm{~kg}$ at the start of mating. The fat ewes were grazed as a follow-upmob behind the preferentially fed thin ewes or lambs. From weaning to the start of mating these ewes gained $6.7 \mathrm{~kg}$ liveweight ( 0.5 condition score units) to average $53.9 \mathrm{~kg}$ at the start of mating. In these on-farm situations, the follow-up ewes performedbetter than the trial follow-up ewes because the pasture had a higher content of ryegrass and white clover.

\section{Practical application}

From the trial results, a broad analysis can be made to compare the likely benefits from preferential feeding of thin ewes and using fat ewes to follow-up with using both thin and fat ewes as follow-up animals as is the general practice on sheep farms. This analysis assumes that there is sufficient pasture available of a type suitable for preferentially feediig thin ewes with the first choice of pasture. The analysis can be carried out by comparing the average ovulation rate and wool production from the preferential thin and follow-up fat groups with the average from the follow-up fat and thin groups. Although this comparison indicates that there is a substantial benefit from preferentially feeding thin ewes, it is based on several assumptions that could not be tested in the trial. These include the lack of actual lambing performance results from the different treatment groups and the assumption that combining treatment groups wouldresultinsimilareweperformancetothatobtained from grazing thin and fat ewes in separate groups. The inclusion of a control group of mixed thin and fat ewes would have allowed a more valid comparison to be made. However Kelly et al. (1983) reported similar performance from light and heavy ewes grazed separately or mixed in one mob for 6 weeks before the start of mating. There would also be some extra costs from implementing the strategy. These include time and possibly labour in individually condition scoring each 
ewe at weaning and shifting an extra mob of sheep. In order to have pasture suitable for preferential grazing of thin ewes, it may also be necessary to dispose of lambs or other priority stock that would normally graze this pasture at an earlier date. However. even after taking these factors into consideration, it is considered that there would be worthwhile benefits from the preferential feeding of thin ewes from weaning to mating.

\section{Conclusions}

Preferentially fed ewes that leniently grazed summer pasture with a low ryegrass and white clover and a high unimproved grass, dead material and weed content gamed 5-6 kg of liveweight from weaning to mating.

To maintain pasture quality for future grazings. it was necessary to carry out a follow-up grazing to control less desirable pasture species and weeds. Ewes used in this role maintained liveweight only from weaning to mating.

3 Separating thin ewes at weaning and preferentially feeding them from weaning to mating resulted in a greater ovulation rate at the start of mating compared with the use of thin ewes in a follow-up grazing role (1.35 vs 1.01). The comparative difference in ovulation rate for preferentially fed and follow-up fat ewes was lower (1.44 vs 1.21 ).

4 The response in wool production from weaning to mating was similar for preferentially fed and follow-up thin ewes (1.01 vs $0.82 \mathrm{~kg} / \mathrm{ewe}$ ) compared with preferentially fed and follow-up fat ewes (1.11 vs $0.91 \mathrm{~kg} / \mathrm{ewe})$.

\section{ACKNOWLEDGEMENTS}

Landcorp for the use of land and animals; H McMillan, JDobbs, H Meijer, S Neal, R Marshall, D O'Connell and M Smith for technical assistance; Dr J Munro for carrying out the laparoscopy measurements; K Thompson for helpful advice; and D and K Baird for statistical analysis.

\section{REFERENCES}

Hawker, H.; Crosbie. S. F.; Thompson, K. F. 1982. Effects of season and pasture allowance on the wool growth of Romney ewes. Proceedings of the New Zealand Society of Animal Production 42: 183-185.

Kelly, R.W.; Thompson. K.F.; Hawker, H.; Crosbie, S.F.; McEwan, J.C. 1983. Liveweight, ovulation rate and wool growth responses of light and heavy ewes to differential feeding. New Zealand Journal of Experimental Agriculture 11: 219224.

Rattray, P. V.; Jagusch, K. T.; Smith, J. F.; Winn, G. W.; McLean, K. S. 1980. Flushing responses from heavy and light ewes. Proceedings of the N ew Zealand Society of Animal Production 40:3437.

Russell, A. J. F.; Doney, J. M.; Gunn. R. G. 1969. Subjective assessment of body fat in live sheep. Journal of Agricultural Science Cambridge 72: 451-54.

Russell A. J. F. 1984. Body condition scoring of sheep. In Practice: 91-93.

Thompson. K. F.; McEwan, J. C.; Kelly. R. W .; Crosbie. S. F. 1983. Ewe liveweight, level of pasture feedmg and liveweight gain. Proceedings of the New Zealand Society of Animal Production 43: 225-227.

Thompson, K. F.; Sedcole. J. R.; O'Connell, D.; Geenty, K. G.; Sykes. A. R. 1990. Spring and summer pasture feeding and ewe reproduction and wool growth. Proceedings of the New Zealand Grass. land Association 52: 123- 127. 